\title{
Cluster Analysis of First-visit Patients' Answers for Japanese-Oriental Kampo Questionnaire Supporting the Empirical Decision of Sho-syndrome
}

\author{
Mitsuyo ISHIZUKA
Masaki TSUDA $^{\mathrm{a}}$ \\ Toshiaki KITA ${ }^{\mathrm{b}}$ \\ Terutaka $\mathrm{KATOH}^{\mathrm{c}}$ \\ Hiroyori TOSA ${ }^{\mathrm{e}}$ \\ Ikuko KIMURA ${ }^{\mathrm{f}, *}$ \\ Hiroshi TSUNEKI ${ }^{\mathrm{f}}$
}

a Department of Food and Nutrition, Toyama College, 444 Gankaiji, Toyama 930-0193, Japan

b Institute of Environment, Health and Field Sciences, Chiba University, 6-2-1 Kashiwanoha, Kashiwa, Chiba 277-0882, Japan

c Department of Public Health, Institute of Natural Medicine, Toyama Medical and Pharmaceutical University

d Mukeidoh Acupuncture and Moxibustion Clinic, 2-126-7 Horikawa-koizumi, Toyama 939-8081, Japan

e Tosa Clinic, 2-18-9 Higashiurawa, Midori-ku, Saitama 336-0926, Japan

f Department of Clinical Pharmacology, Graduate School of Pharmaceutical Sciences, Toyama Medical and Pharmaceutical University, 2630 Sugitani, Toyama 930-0194, Japan

\section{和漢診療初診者への問診表クラスター分析と“証” \\ 石塚 盈代 $\mathrm{a}$ 喜多 敏明b 加藤 輝隆 $\mathrm{c}$ \\ 津田 昌樹 $\mathrm{d}$ 土佐 寛順e 恒枝 宏史 $\mathrm{f}$ \\ 木村 郁子f,*}

a 富山短期大学・食物栄盖学科, 干930-0193 富山市願海寺444

b 千葉大学・環境健康都市園芸フィールド科学教育研究センター・環境健康総合科学部門，千葉，

富山医科薬科大学・医学部·公衆衛生学, 富山, 干930-0194 富山市杉谷2630

$\mathrm{d}$ 夢恵堂鍼尒院，富山， =939-8081 富山市堀川小泉町2-126-7

土佐クリニック，埼玉， テ336-0926 さいたま市緑区東浦和2-18-9

f 富山医科薬科大学・大学院薬学研究科・臨床薬理学, 富山, =930-0194 富山市杉谷2630

\begin{abstract}
Sho-syndrome was analyzed by cluster analysis of answers to a set of questionnaire presented to first-visit patients at a hospital of Japanese-Oriental (Kampo) medicine. The answers from 270 new patients were classified into 3 groups by hierarchical cluster analysis, with a total of 202 non-female related items. We looked at which Sho-syndromes of metabolic (Mb: “Kan-"肝-), gastrointestinal (Gi : “Hi-"脾-), respiratory (Rp : “Hai-”肺-), or water and mineral-balance (Wm : “Zin-"腎-) deficiency (“Kyo”虚) disorders were included, in one of the groups at high frequencies. Water and mineral-balance deficiency disorders were in Group II and III, while metabolic deficiency disorders were in Group III. We conclude that the results of this analysis support the rationale for the empirical determination of Sho-syndrome, in addition to pulse diagnosis by Kampoclinicians who examine patients.

Key words : hierarchical cluster analysis, first-visit patients' answers to Kampo questionnaires, Shosyndrome

\section{要旨}

富山医科薬科大学付属病院、和漢診療部に来院した初診患者270名に対して，203項目についてアンケートした結 果をクラスター分析した。問診項目を項目間の近接度から3 群に分類できた。各群における肝虚・脾虚・肺虚・腎 虚の 4 つの「証」に相当する質問項目の総出現頻度を比較し, クラスタ一解析結果との対応を検討した。その結果，3 群の中の 1 群に, 肝虚の「証」頻度が極めて高く, その構成質問表はその「証」診断に重要であることが, 裏付け られた。

キーワード : クラスター分析, 問診表, 証
\end{abstract}




\section{Introduction}

Sho-syndrome in patients is diagnosed or determined by Kampo clinicians with medical examination of seeing, hearing, asking and touching. Metabolic (Mb, "Kan-" 肝-), gastrointestinal ( $\mathrm{Gi}$, “Hi-"脾-), respiratory ( $\mathrm{Rp}$, “Hai-"肺-), and water and mineral-balance (Wm, "Zin" 腎-) deficiency (“kyo”虚) disorders in Sho-syndrome are mainly used to consider in the traditional JapaneseOriental Kampo medicine especially in the area of acupuncture and moxibustion. However, very little theoretical rationale has been proposed in the approach to Shosyndrome $^{1 / 2}$ although a large database and libraries have been accumulated on the pharmacology of Kampo medicines. Empirically Kampo clinicians make determination of the Sho-syndrome for the first-visit patients by reviewing their answers to the questionnaire in addition to pulse diagnosis. In the present study, we analyzed the answers provided by 270 patients to the questionnaires with hierarchical cluster analysis in order to decide which questionnaire is rationally fitted to Sho-syndrome used in the area of acupuncture and moxibustion. The use of Shosyndrome, however, is not easily understandable in terms of modern western medicine. For instance, the respiratory deficiency disorders are considered to cause or be related to skin dysfunctions ; the metabolic deficiency disorders are considered to be caused by irregular blood (essential nutrients)-supplying into organs and to worsen the functions of muscles and nervous systems; and the water and mineral-balance deficiency disorders affect water metabolism, bone formation and reproduction.

\section{Methods}

Japanese-Oriental Kampo questionnaire is made with reference to the classical literature of $K a m p o^{3 i-6)}$ in order to decide on the Sho-syndrome, which includes metabolic (Mb, “Kan-”肝-), gastrointestinal (Gi, “Hi-"脾-), respiratory (Rp, “Hai-"肺-), and water and mineralbalance (Wm, “Zin-"腎-) deficiency (“kyo”虚) disorders. Patients on their first visit to the Department of the Japanese-Oriental Kampo Medicine, University Hospital of Toyama Medical and Pharmaceutical University in 1998 were surveyed about their health conditions using the "Japanese-Oriental Kampo Medicine Questionnaire of Health". The patients were requested to answer the questionnaire regarding their health status. Then, the medical doctors reviewed each patient's completed questionnaire during a medical examination.

Sixteen categories, totaling 215 items (including two sub-questions), were included in the questionnaire. Items are composed of (1) 19 items on the constitutional symptoms (including two sub-questions), (2) 11 items on defecation, (3) 8 items on voidance and/or the property of urine, (4) 7 items on appetite, (5) 8 items on sleep, (6) 8 items on sweating, (7) 19 items on feeling hot/chilled, (8) 11 items on the mouth and tongue, (9) 20 items on the head, (10) 16 items on the face and eyes, (11)14 items on the ears and nose, (12) 12 items on chest symptoms, (13) 18 items on the abdomen, (14)12 items on the skin conditions, (15) 19 items on the joints, hands and feet, and (16) 13 items on the menstruation. Some items of the questionnaire were considered by clinical Kampo doctors (Kita T, Tsuda M, and Tosa $\mathrm{H}$ ) to correspond to four types of deficiency ("kyo"虚) disorders, referred to as the following Kampo ${ }^{(3)}$ systems: metabolic (including blood reservation, supplying nutrients, and control of muscles and nervous system) (Mb, “Kan-”朋-), gastrointestinal (including food-digestion, food-transformation, and water metabolism) (Gi, “ $\mathrm{Hi}$-"脾-), respiratory (including skin and respiration) (Rp, “Hai-"肺-), and water and mineral-balance (including water metabolism, bone formation, and reproduction) (Wm, "Zin-"腎-) deficiency disorders.

Patients marked 0 (no), 1(yes, but only occasionally), 2 (yes, often), 3 (yes, almost always), and 4 (yes, always). Each patient $(n=582$, both male and female) who visited the Department from January to December in 1998 was surveyed. Cluster analysis was carried out for the $270 \mathrm{pa}-$ tients who answered all 199 items (16 items were excluded from the total of 215 , see details below). Since the other 312 patients did not check some items, their answers were excluded from the present analysis. The hierarchical cluster analysis was performed with Euclidean distance calculated by Ward method ${ }^{7}$. Smaller Euclidean distances shown at the abscissa of Fig.1 A indicate closer association. Answers by workers to some items of questionnaire were reproduced $^{8,9 !}$.

A few items were eliminated, including 13 items on menstruation, and 3 items on perspiration, which overlapped with other items (see Results). The items for female-related symptoms (102 headache and menstrual days are related, 186 relationship between joint pain and menstruation, 203 be postmenopausal, 204 menopause occurred due to an operation, 205 regular menstruation, 206 irregular menstruation over a week, 207 menstruation is only 2-3 days, 208 menstruation term continues over a week, 209 had an abortion (how many), 210 had a miscarriage (how many), 211 discharge from the womb, 212 mass of menstrual blood, and 213 need to take drugs and rest because of menstrual pain) were not used in the cluster analysis. Female-related syndrome is strongly contributed to causation of "Sho"-syndrome. However, because the answers for the items of No.203 to No.208 were consisted of binary scores (yes or no), the items were unable to be analyzed together with the other items.

\section{Results}

We surveyed 582 patients from the Japanese-Oriental Kampo Medicine Department in 1998 to analyze 202 items, which consisted of 15 branch numbers and excluded the 13 items on menstruation. No items on the 
questionnaire were left unanswered. Answers for 53 (wake-up fretful), No.54 (perspire a lot), No.63 (always feel cool), No.155 (feel sick in the morning when using toothpaste), and No.170 (tight-stretched back) showed the highest marks, and only one patient refrained from answering these items. No.97 item (feel fine when there is no headache) showed the lowest frequency in marks, only 55 patients responded, suggesting that the meaning of No.97 was ambiguous. No.15 item (decrease in carnal desire) also had a low frequency of responses (49 patients).

There were 8 items concerning patient perspiration. The meanings of items No.54 (sweat a lot) and No.57 (seldom sweat) were overlapped with items No.55 (sweat is not viscid) and No.56 (sweat is viscid), respectively. As the frequency of response for these overlapping items were low ( $n=33$ and $n=18$, respectively), these 3 items of sweating (No.55, 56, and 57) were not included in the cluster analysis. Finally we adopted the data of 270 patients composed of 103 men, 155 women, and 12 unknown (not answered) patients. Their ages were 6 (0-9 years old), 18 (10-19 years old), 57 (20-29 years old), 48 (30-39 years old), 41 (40-49 years old), 33 (50-59 years old), 28 (60-69 years old), 23 (70-79 years old), 4 (80-89 years old), and 12 unknown (not answered) in 1998.

Hierarchical cluster analysis by Ward method on 199 items of the questionnaires No.1 to No.202 are shown in Fig.1 A with dendrogram (a branching pattern of construction) which was developed to classify the distribution of answers to questionnaire in 270 patients. The abscissa by dendrogram using Ward method indicates a rescaled distance cluster combine. The smaller values indicated closer relations. An item number in the questionnaire was shown in an ordinate axis. Items of questionnaires were arranged and grouped depending on the degree of clustering. In the main hierarchical clusters, the questionnaire was mainly over for Group I, II and III depending on the levels of $\mathrm{A}, \mathrm{B}, \mathrm{C}$, and $\mathrm{D}$ (rescaled distance cluster combine in a horizontal axis of Fig. 1 A). The same results were obtained by group average method instead of Ward method (data not shown).

The Sho-syndrome of metabolic (Mb: “Kan-"肝-), gastrointestinal (Gi : "Hi-"脾-), respiratory (Rp : "Hai-" 肺-), and water and mineral-balance (Wm: “Zin-”腎-) deficiency ("kyo"虚) disorders is considered empirically by Kampo clinicians. The Sho-syndrome, included as the items of the questionnaires listed is shown at the end of text. From Fig.1, the answers by patients were mainly classified into 3 groups of I, II, and III which consist of 74,88 , and 37 items, respectively. In each group the frequencies of Sho-syndrome of $\mathrm{Mb}, \mathrm{Gi}, \mathrm{Rp}$ and $\mathrm{Wm}$ were compared. The frequencies were $(\mathrm{Mb}) 8(\mathrm{Gi}) 8(\mathrm{Rp}) 0$ (Wm) 5 for 74 items in Group I (Questionnaire No.43 to No.184), (Mb) 6 (Gi) 11 (Rp) 6 (Wm)13 for 88 items in Group II (Questionnaire No.177 to No.106), and (Mb) 8
(Gi) $5(\mathrm{Rp}) 3(\mathrm{Wm}) 5$ for 37 items in Group III (Questionnaire No.8 to No.53). In subgroup III', high frequencies of Sho-syndrome per an item were observed : (Mb) 5(Gi) 4 (Rp) 3 (Wm) 5 for 22 items (Questionnaire No.67 to No.53). Sho-syndrome appeared frequently in the answers by patients to Group III questionnaires, especially in subgroup III'. Respiratory deficiency syndrome (Rp) was not included in Group I, but at the same ratio in Groups II and III. Water and mineral-balance deficiency syndrome $(\mathrm{Wm})$ was reported twice more frequently in Groups II and III than that of Group I. The ratio of metabolic deficiency syndrome ( $\mathrm{Mb}$ ) was highest in group III. The ratios of gastrointestinal deficiency syndrome (Gi) were not discriminated among three groups.

\section{Discussion}

Cluster analysis has been medically applied in various attempts to form typologies consisting of clustered categories that form subgroups for a particular ailment. Cluster analysis has been used to support subgroups for the clinical spectrum of disease. Clinicians often construct such subgroups subjectively with staging systems for various forms of disease nosology, and many other purely clinical sub-classifications. With cluster analysis methods, these subjective assessments are replaced by a formal mathematical approach. The main operational strategies in cluster analysis involve the choice of mechanisms for measuring the similarity or affinity of different questionnaires. This different, more objective, tactics used for this purpose create a complex array of strategies. The goal of cluster analysis is to divide the questionnaire into an appropriate set of categorical clusters. Each item is assigned to a single clustered location. In a tree, the hierarchical group allows items to be grouped under a Shosyndrome of clusters. Not all items necessarily belong to the Sho-syndrome. The items used were considered as ordered categorical variables in the present cluster analysis. When cluster analysis is done mathematically with a hierarchical method, the direction is starting with individual items of questionnaire that are successively combined to form the family groups.

Sho-syndrome in patients is considered by Kampo clinicians with medical examination of seeing, hearing, touching and questionnaires in addition to pulse diagnosis. Metabolic (Mb, “Kan-"肝-), gastrointestinal (Gi, "Hi-" 脾-), respiratory (Rp, “Hai-"肺-) and water and mineralbalance (Wm, “Zin-"腎-) deficiency (“kyo”虚) disorders are the main categories used to describe the Shosyndrome of traditional Japanese-Oriental Kampo medicine, especially in the area of acupuncture and moxibustion. Sho-syndrome is usually determined empirically by the Kampo clinicians with experiences. In the present study, one group (Group III) of the three groups of the questionnaire categorized by cluster analysis revealed the high frequency of Sho-syndrome. Since some items were 

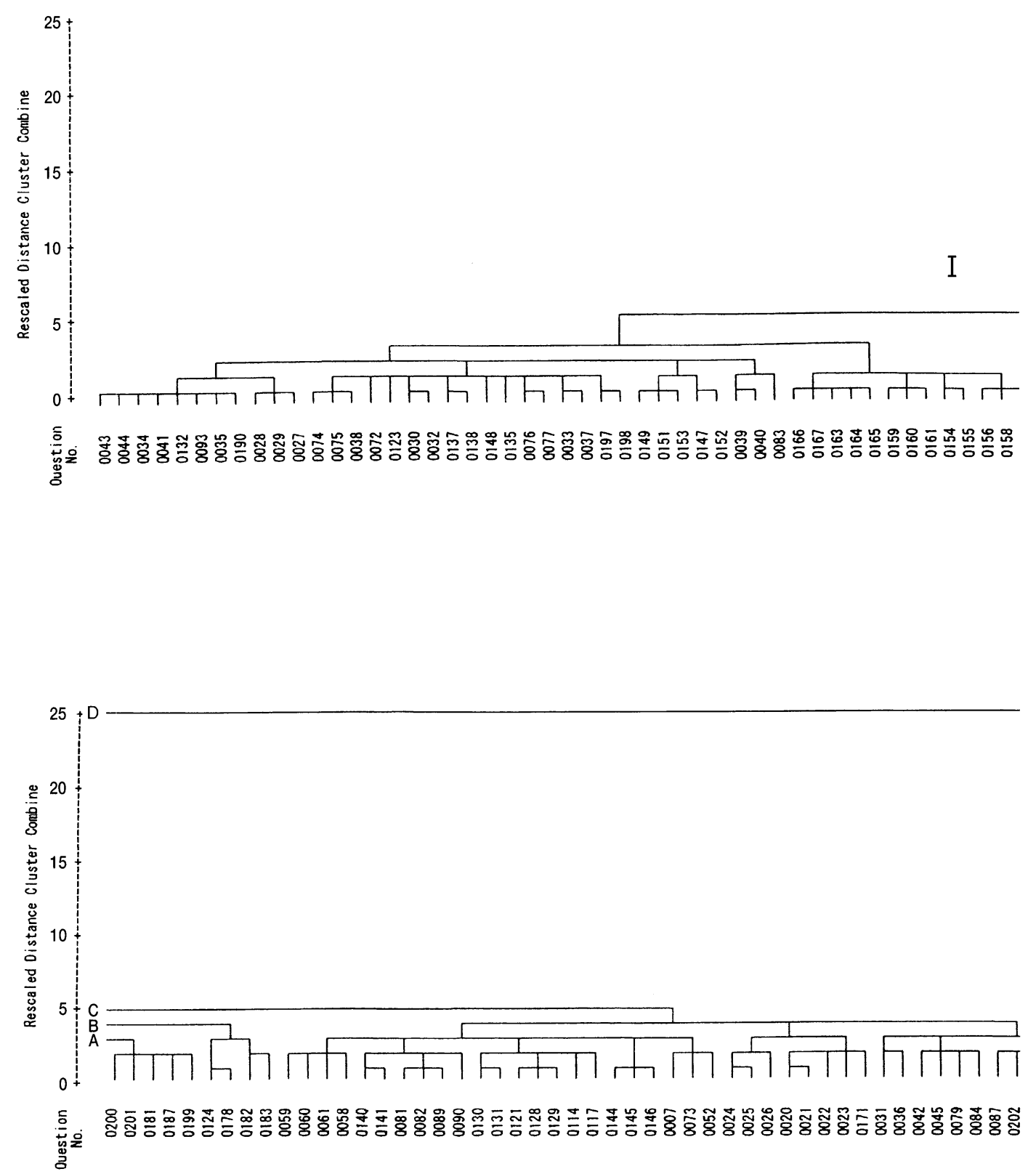

Fig.1 A Cluster analysis of answers by first-visit patients to questionnaires (199 Medical and Pharmaceutical University Hospital, using Ward method.

Dendrogram showing distribution of answers in patients $(n=270)$, and subsequent A few items were eliminated, including 13 items (No.102, No.186, and No.203 to other items (detailed in text). Horizontal lines indicate rescaled distances among clusnate line is ranked questionnaires shown as follows.

Questionnaires ranked at horizontal axis of Fig.1 A are shown at the end of text. Kampo bolically called as metabolic ( $\mathrm{Mb}$ : “Kan-”肝-), gastroenterological (Gi : “ $\mathrm{Hi}$-”脾-), 虚) syndrome. 


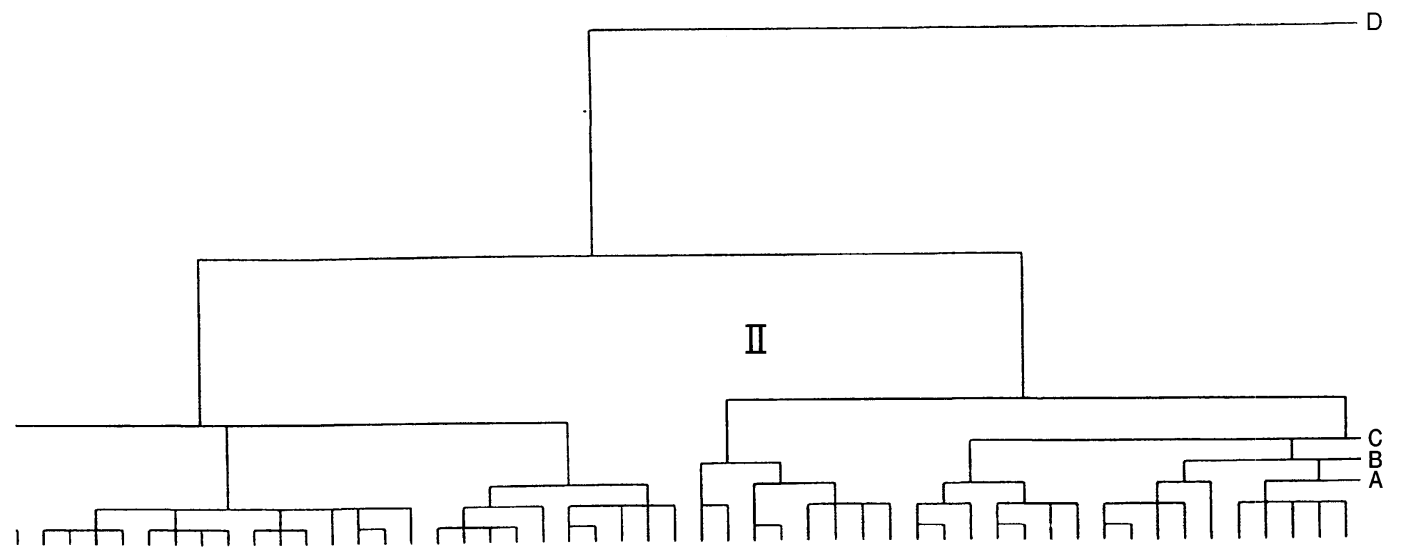

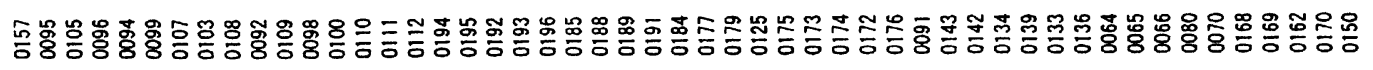

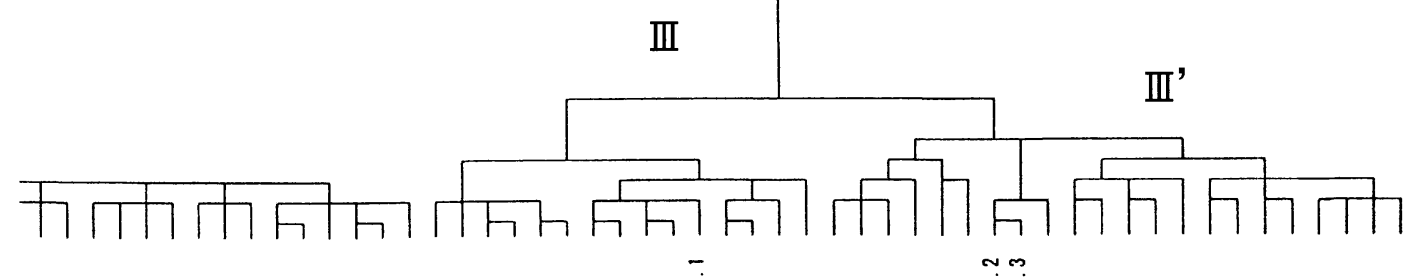

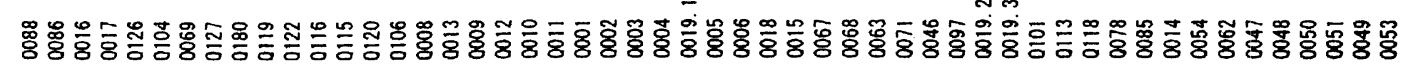

items from No.1 to No.202) on health at Japanese-Oriental Kampo Medicine of Toyama

hierarchical formation of three main groups and a subgroup, marked I, II, III, and III'. No.213) on menstruation, and 3 items on perspire (No.55 to No.57) overlapped with ters, where a smaller value means a closer relationship among questionnaires. An ordi-

clinicians prescribe Kampo medicines to patients suffering from (Sho-symptoms) symrespiratory (Rp:"Hai-"肺-), and water and mineral (Wm:“Jin-”腎-) deficiency (“-kyo"- 
$10 \quad 20 \quad 30 \quad 40 \quad 50 \quad 60 \quad 70 \quad 80 \quad 90 \quad 100110120130140150160170180190200210$
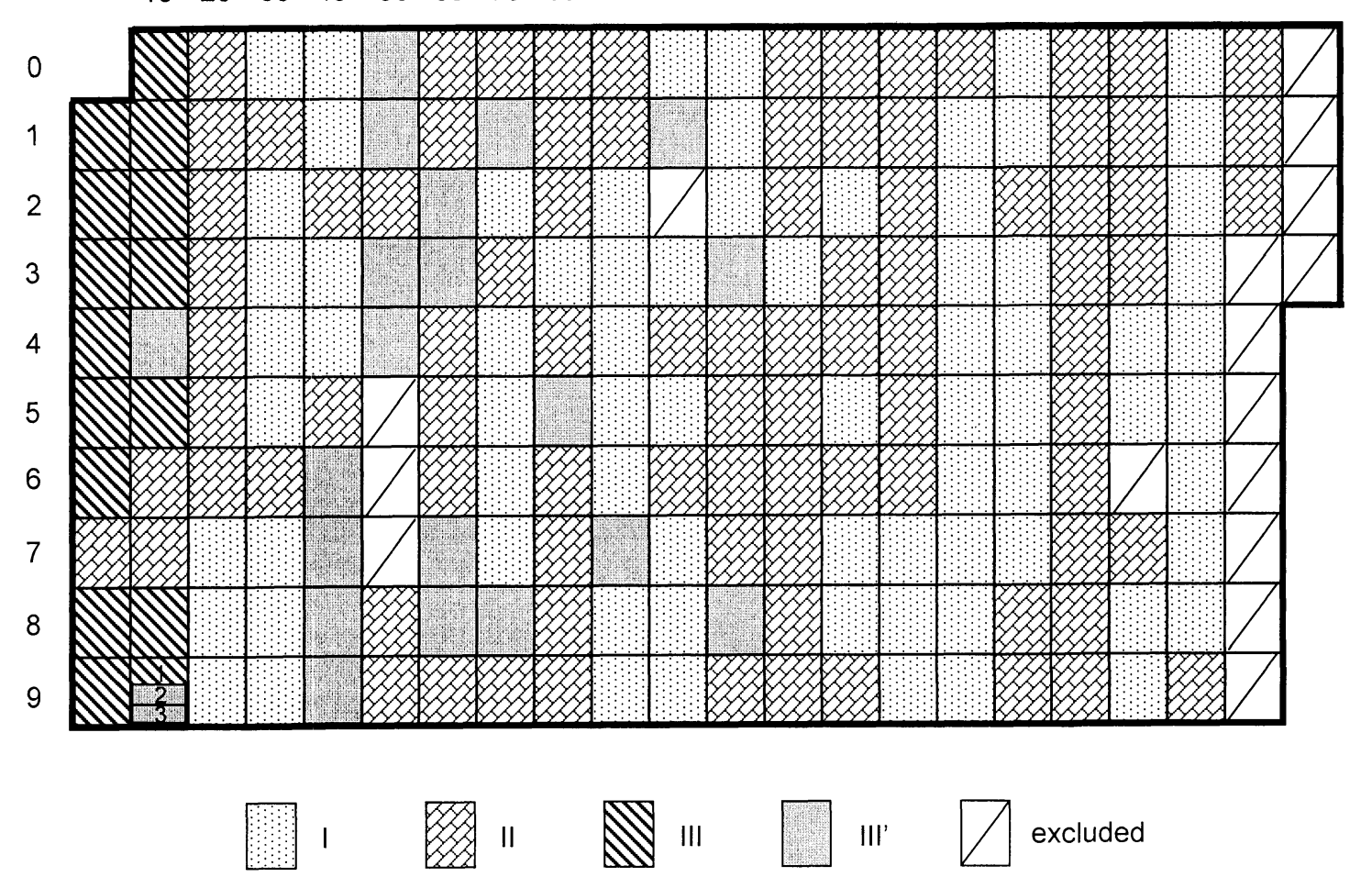

Fig.1 B Summary of the results of cluster analysis. Each grid (from No.1 to No.213) represents the questionnaire with the same number as shown above. The grids were marked on the basis of their subgroup (I, II, III and III').

correlated with each other, it is important to select related items with principal component analysis followed by cluster analysis. Although some Sho-syndrome is overlapped in several questionnaires, cluster analyses can discriminate among the syndrome. Group I and II were widely dispersed in questionnaires as shown in Fig.1 B. Group III, especially group III' was thought to play important roles in deciding Sho-syndrome. It seems rather preferable to permutate the order in questionnaires presented depending on Group I, II, III, and III'.

Of the 4 main categories described above, respiratory deficiency syndrome (Rp) was not included in Group I. Water and mineral-balance deficiency syndrome (Wm) was contained mainly in Groups II and III, and metabolic deficiency symptoms $(\mathrm{Mb})$ were highest in Group III. The ratios of gastrointestinal deficiency symptoms (Gi) were not distinguished among the three groups. Rationale grouping and rearrangement of questionnaires are suggested by the present analyses. It may potentially contribute for the Kampo physicians to efficiently decide patient Sho-syndrome.

The results of cluster analyses were restricted to deficiency (“kyo"虚) disorders in Sho-syndrome in the area of acupuncture and moxibustion. Excess (“jitu”実) disorders can also be analyzed using the same approach. We conclude that the results of this analysis support the rationale for the Kampo physicians to use the questionnaire system to reach the empirical decision of Sho-syndrome.

\section{Acknowledgments}

The authors thank to Dr. K. Terasawa (previous Vicepresident, Toyama Medical and Pharmaceutical University) and Dr. M. Kasuya (Director, Toyama Occupational Health Promotion Center, Labor Welfare Corporation) for their kind comments and discussions, and Dr. Shaw T. Chen (Associate Director, Food \& Drug Administration, Center for Drug Evaluation, and Research, MD, USA) for his critical reading of the manuscript.

\section{References}

1) Suganuma, S. : Traditional Chinese medicine on gastrointestinal diseases. Kampo Medicne 54, 445-448 (2003)

2) Ohsawa, N. : What is EBM of Kampo medicine?, Kampo Medicine 54, 548-551 (2003)

3 ) Terasawa, K. : Kampo ; Japanese-Oriental Medicine Insight from Clinical Case, Standard Mcntyre (1993)

4 ) Kosoto, T., Hamada, T. : Iyaku-81-Nankyou, Tsukiji Shokan (1971)

5 ) Kosoto, T., Hamada, T. : Iyaku-KhoteidaikyouShomon, Tukiji Shokan (1971)

6 ) Kosoto, T., Hamada, T. : Iyaku-Khoteidaikyou-Reisuu, Tukiji Shokan (1972)

7 ) Tanaka, U., Tarumi, T., Wakimoto, K.(Eds.) : Handbook on Statistical Analysis by Personal Computer Programms, II. Multivariate Analysis, KyoritsuShuppan (1985)

8 ) Ishizuka, M., Tsuda, M., Tosa, H. : Survey of feelings 
of fatigue based on the concept of "Sho", Hiro to Kyuuyo no Kagaku, 10, 119-130 (1995)

9 ) Ishizuka, M., Tsuda, M., Tosa, H. : Survey of feelings of fatigue based on the concept of "Sho"-II, Hiro to Kyuuyo no Kagaku, 12, 103-113 (1997)

\section{Group I :}

43 (Can not recognize the taste of foods), 44 (Bitter taste in the mouth, Gi), 34 (Pain when urinating), 41 (Good appetite, but can not eat), 132 (Frequent nosebleeds), 93 (Foreboding of an ictus), $\mathbf{3 5}$ (Occasional incontinence), 190 (Water stands in the joints), 28 (Recent blood mixed stools), 29 (Recent jell-like stools), 27 (Recent swarthy stools)

74 (Suddenly feel hot or cold on the spine), 75 (Feel hot, during the evening), 38 (Dilute urine), 72 (Feel hot in the whole body), 123 (Volitant like a black mosquito in eyes), 30 (Recent small caliber stools), 32 (Decreased urinary output and frequency), 137 (Lump in the throat by foods, Mb, Wm), 138 (Choke by food and drinks), 148 (Throat of strider), 135 (Can not distinguish smell), 76 (Hot palms), 77 (Soles of feet are flushed, Wm), 33 (Residual urine, Not urinate absolutely, Wm), 37 (Take a long time to void urine), 197 (Tremulous hands), 198 (Muscle twitch, Mb)

149 (Chest distress), 151 (Wake-up with a gloomy feeling), 153 (Irregular pulse and uneasy feeling after singultous-like symptom), 147 (Occasionally deep chest pain), 152 (Distress on the side of the chest, $\mathbf{M b}$ ), 39 (Loss of appetite, $\mathbf{M b}, \mathbf{G i}$ ), $\mathbf{4 0}$ (Eat unless loss of appetite), 83 (Dry in mouth)

166 (Pain at the left side of the stomach), 167 (Pain at the right side of the stomach), 163 (Stomachache), 164 (Pain around the navel), 165 (Pain at the under abdomen), 159 (Heaviness in the pit of the stomach, Mb, Gi), 160 (Pain in the pit of the stomach), 161 (Heaviness around the heart and ribs), 154 (Often nauseous, Gi), 155 (Feel sick in the morning when using tooth past), 156 (Belching, Gi), 158 (Rising of gastric juice in the mouth), 157 (Occasional heartburn)

95 (Headache as if the head is pressed a heavy stones, Gi), 105 (Feel heavy as if wearing helmet), 96 (Regular headache almost everyday), 94 (Splitting headache), 99 (Ache of the forehead), 107 (Feel nausea and vomit when you have a headache), $\mathbf{1 0 3}$ (Always take medicine for a headache), 108 (Often have a headache in the morning, Mb), 92 (Throbbing head, Mb), 109 (Often have a headache in the evening), $\mathbf{9 8}$ (Ache at the temple and top of the head), 100 (Headache on the occiput), 110 (Headache relates to the weather), 111 (Headache caused by a crowd), 112 (Swollen eyelids)
194 (Stiffen body, moving is difficult), 195 (Giddy feeling, walking is difficult), 192 (Paralysis of half the body), 193 (Paralyzing), 196 (Stumble easily), 185 (Swollen and feverish joints, Gi, Wm), 188 (Pain during seasonal change), 189 (Stiff hands in the morning), 191 (Unable to sit straight, because of knee-pain), 184 (Arthralgia, Mb, Gi, Wm)

\section{Group II :}

177 (Dry skin, Rp), 179 (Itchy skin), 125 (Easily break out with pimples on facial skin), 175 (Often have eruptions and pimples), 173 (Constant hives), 174 (Maturated easily), 172 (Constant ache), 176 (Sudden rash), 91 (Watery sputum), 143 (Cough up a lot of phlegm, Gi), 142 (Can not stop coughing), 134 (Frequent nasal congestion), 139(Unclear feeling around the throat and nose), 133 (Runny nose, Rp), 136 (Frequent sneezing)

64 (Feel a chill in the whole body), 65 (Feel cold on the spine), 66 (Feel a chill around the hips), 80 (Feel a chill when disrobed or exposed wind), 70 (Dislike a cooler), 168 (Bowl sometimes rumble), 169 (Feel gassy), 162 (Bloated stomach, Gi, Wm), 170 (Tight-stretched back), 150 (Sigh without knowing why, Mb, Gi, Wm), 200 (Frequent cramps in the calf, Mb), 201 (Numb finger tips and feet), 181 (Easily bruised), 187 (Swollen legs, Gi, Wm), 199 (Joint pain when catch a cold and feel feverish), 124 (Increase in dark pigmentation of facial skin), 178 (Increased spots), 182 (Hair is $\operatorname{dim}$ ), 183 (Lose hair easily)

59 (Perspire at night, Wm), 60 (Sweat spasms), 61 (Sweaty palms), 58 (Perspiration at night), 140 (Always have a sore throat, Rp, Wm), 141 (Husky voice), 81 (Sticky mouth, Gi), 82 (Saliva accumulates in the mouth), 89 (Inarticulate), 90 (Bad breath)

130 (Ringing in the ears, Wm), 131 (Hear an inaudible sound), 121 (Transiently blinded), 128 (Dizziness, Mb), 129 (Vertigo when standing up, Wm), 114 (Be dazzling), 117 (Dim sight), 144 (Shortness of breath, Rp, Wm), 145 (Heart palpitation), 146 (Pulse is not normal), 7 (Skittish about everything, Wm), 73 (Feel hot in the upper body, especially on the face), $\mathbf{5 2}$ (Wake-up early in the morning)

24 (Soft feces), 25 (Diarrhea, Gi, Wm), 26 (Constipation and diarrhea are repeated alternately), $\mathbf{2 0}$ (Hard stools), 21 (Mbttle stools / like rabbits), 22 (Bowel movement everyday, but uncomfortable), $\mathbf{2 3}$ (Constipation, Gi, Wm), 171 (Hemorrhoids, Gi, Rp)

31 (Desire to urinate after a short time, Rp, Wm), 36 (Get up in the middle of the night to urinate, $\mathbf{W m}$ ), 42 (Strong appetite, overeat carelessly, Gi), 45 (Desire to eat 
sweets, Gi), 79 (Like lukewarm bath), 84 (Drink a lot of cold water), 87 (Perleche on the corners mouth), 202 (Fingers turn white or purple, when your hands get cold), 88 (Rough lips, Gi), 86 (Stomatitis, Gi)

16(Motion sickness), 17 (Fragile fingernails), 126 (Pale complexion, Rp), 104 (Strong stiffness of shoulders with a headache), 69 (Have chilblains), 127 (Ruddy face), 180 (Caps in the winter), 119 (Bloodshot eyes, Mb), 122 (Eye mucus), 116 (Itchy eyes), 115 (Something lies scattered in the eyes, Mb), 120 (Dry eyes), 106 (Sore eyes in the inner part, $\mathbf{M b}$ )

\section{Group III :}

8 (Memory failure, Mb), 13 (Unable to maintain interest in things), 9 (Irritability, Mb), 12 (Feel angry, Mb), 10 (Feel nervous), 11 (Anxious about small things), 1 (Easy fatigability), 2 (Tired in the next morning), 3 (Feel unwell in some way), 4 (Lack of will power), 19.1 (To moving is irked), 5 (Heaviness in the whole body, Gi), 6 (Heaviness in the legs and loins), 18 (Weak hips and knees), 15 (Decrease in carnal desire)

\section{Group III' :}

67 (Feel a chill under the hips), 68 (Cold hands and feet, Mb, Rp, Wm), 63 (Always feel cool, Rp, Wm), 71 (Need electric blankets in winter), 46 (Can not get to sleep), 97(Feel fine when there is no headache), $\mathbf{1 9 . 2}$ (Stiff shoulder, right, Mb, Gi, Wm), 19.3 (Stiff shoulder, left, Mb, Gi, Wm), 101 (Stiff neck)

113 (Strained eyes), 118 (Eyesight has deteriorated, Wm), 78 (Like hot bath), 85 (Drink a lot of warm tea or water), 14 (Easily catch a cold, Rp), 54 (Perspire a lot), 62 (Always feel hot), 47 (Often wake up in the night, Mb), 48 (Sleep lightly, Mb), 50 (Desire to sleep after meals, Gi), 51 (Drowsiness, Gi), 49 (Often have dream), 53 (Wake-up fretful) 